\title{
Region-based MTI: resolving geographic expansion in the Marine Trophic Index
}

\author{
K. Kleisner ${ }^{1,3, *}$, H. Mansour ${ }^{2,3}$, D. Pauly ${ }^{1}$ \\ ${ }^{1}$ Sea Around Us Project, Fisheries Centre, University of British Columbia, 2202 Main Mall, Vancouver, BC V6T 1Z4, Canada \\ ${ }^{2}$ Earth and Ocean Sciences, University of British Columbia, 2207 Main Mall, Vancouver, BC V6T 1Z4, Canada \\ ${ }^{3}$ Present address: NOAA, Northeast Fisheries Science Center, 166 Water St., Woods Hole, MA 02543, USA
}

\begin{abstract}
The Marine Trophic Index (MTI), which tracks the mean trophic level of fishery catches from an ecosystem, generally, but not always, tracks changes in mean trophic level of an ensemble of exploited species in response to fishing pressure. However, one of the disadvantages of this indicator is that declines in trophic level can be masked by geographic expansion and/or the development of offshore fisheries, where higher trophic levels of newly accessed resources can overwhelm fishing-down effects closer inshore. Here, we show that the MTI should not be used without accounting for changes in the spatial and bathymetric reach of the fishing fleet, and we develop a new index that accounts for the potential geographic expansion of fisheries, called the region-based MTI (RMTI). To calculate the RMTI, the potential catch that can be obtained given the observed trophic structure of the actual catch is used to assess the fisheries in an initial (usually coastal) region. When the actual catch exceeds the potential catch, this is indicative of a new fishing region being exploited. The MTI of the new region can then be calculated, and subsequent regions are determined in a sequential manner. This method improves upon the use of the Fishing-in-Balance (FiB) index in conjunction with the original MTI calculated over the whole time series because assumptions of fleet and stock stationarity over the entire time series and geographic area are removed. We illustrate the utility of the RMTI with simulated examples and actual data, and generalize these results.
\end{abstract}

KEY WORDS: Mean trophic level · Indicators · Expansion of fishing · Fishing-in-Balance Index

\section{INTRODUCTION}

Numerous studies indicate that humans are rapidly altering the planet's ecosystems, notably the oceans (e.g. Jackson et al. 2001, Halpern et al. 2008). Human activities, including heavy fishing pressure, impact the health of the marine environment by destroying natural habitat, increasing pollution, decreasing biomass, and altering biodiversity (Vitousek et al. 1997, Pauly et al. 2005), and are compounded by a burgeoning human population with a growing appetite for seafood. Loss of biodiversity is a particularly insidious problem that is more difficult to visualize in the marine environment than on land (Pauly et al. 2000a) due to the remoteness of this vast resource and the fact that we often lack a historical perspective on the extent to which we have affected the ocean. The latter problem is known as the 'shifting baselines syndrome' (Pauly 1995), whereby each generation accepts that the current (or relatively recent) stock size and species composition is the baseline for evaluating the current trends in the fishery. Unfortunately, with the increasing number of stocks that are overexploited or have collapsed (Froese \& Kesner-Reyes 2002, Kleisner et al. 2013a), there is a growing need to measure the impact of these processes with global indicators of marine status that are spatially and temporally robust. Indices, unlike direct measurements, provide the benefit of interpretability by scientists and policy makers 
(O'Connor \& Dewling 1986). Unfortunately, reliable indicators of such impacts are still scarce despite their potential usefulness.

To date, 2 indices exist from which changes in trophic level over time can be inferred, namely, the Mean Trophic Index (MTI) and the Fishing-in-Balance (FiB) index (Pauly et al. 1998a, 2000b, Pauly \& Watson 2005, Bhathal \& Pauly 2008). The MTI is built on the concept of 'fishing down marine food webs,' whereby fisheries will tend to target first the larger, longerlived species on top of marine food webs (so far as gear are available that are capable of catching them), and as those larger and less resilient species become depleted, subsequently increase fishing pressure on smaller species (Pauly et al. 1998a). The idea behind the MTI is that, when this happens, there will be a decline of the mean trophic level of the overall catch, due to a progression from intense fishing pressure on the highest trophic levels at the start of the fishery to increasing pressure on the lower trophic levels as the abundance of high trophic level species declines. Given that the MTI has been proposed as an index of the biodiversity of top predators (Pauly \& Watson 2005), several 'cutoff' points for MTI, whereby lower trophic level species with high biomass are excluded, have been proposed and used (e.g. Pauly \& Watson 2005, Stergiou \& Tsikliras 2011, Babouri et al. 2014). There has been a good deal of debate around the concept of MTI (or cutoff-MTI) and the idea of fishing down (see e.g. Caddy et al. 1998). In response, some alternative hypotheses have been proposed to explain other patterns. For example, Essington et al. (2006) showed that in the North Atlantic, fishing down is an observable phenomenon. However, they suggested that in other regions of the world, the pattern of change in trophic level may be better described as 'fishing through' the food web, marked by successive addition of lower trophic levels when fisheries focus on this segment of the ecosystem rather than the higher trophic levels. More recently, Branch et al. (2010) questioned the ability of catch-based MTIs to reflect changes in the mean trophic level of the ecosystem and biodiversity, and compared catch-based MTIs in large marine ecosystems (LMEs) with surveybased MTIs. However, that study did not consider fishing fleet movements and the possibility that the catches used to compute the catch-based MTIs were taken from different areas over the time series especially in contrast to survey-based data, which should come from a standardized area. The utility of catch data for resolving patterns and shifts in ecosystem health has recently been debated in the form of contrasting essays (Pauly et al. 2013).
The existence of 'fishing down' was initially documented globally with FAO landings data from 1950 to 1994, combined with estimates of trophic levels from 60 published mass-balance trophic models from every major aquatic ecosystem type (Christensen \& Pauly 1993, Pauly \& Christensen 1993, 1995, Christensen 1995). Since it was first proposed in 1998, the notion that we are 'fishing down' in some regions has been corroborated through numerous studies on a large number of marine and freshwater ecosystems (Jackson et al. 2001, Myers \& Worm 2003, Bellwood et al. 2004, Hutchings \& Reynolds 2004, Frank et al. 2005, Scheffer et al. 2005, Morato et al. 2006, Gascuel et al. 2007, Bhathal \& Pauly 2008, Coll et al. 2010, Pauly 2010; see also www.fishingdown.org).

The MTI works best when the catch time series that is available pertains to a well-defined area and/or depth range, in which all major species are accessible from the onset. These conditions, which were not stated and not met in the study of Pauly et al. (1998a), could be the reason why a number of FAO statistical areas, at the time, did not seem to exhibit 'fishing down.' Unfortunately, the MTI is often calculated from data pertaining to large areas, e.g. the FAO statistical areas, large exclusive economic zones (EEZs), or LMEs (Branch et al. 2010), within which fisheries have expanded over time, with the result that the fishing-down effect is partly or completely masked (Bhathal \& Pauly 2008). In such cases, the MTI would indicate that the overall trophic level is stable or has even increased, while the trophic level of the initial region may have in fact declined (Fig. 1).

The FiB index was designed to account for the expansion and contraction of the fishing fleet over time as reflected by the trophic level of the catches (Bhathal \& Pauly 2008). Thus, for a given region, the FiB index relates the catches and average trophic level in a given year to the catches and average trophic level in an initial year to determine whether the change in mean trophic level is compatible with the transfer efficiency (TE) of that region. For example, when the TE is $10 \%$, a decline or increase in 1 trophic level in MTI should correspond to a 10-fold increase or decrease in catches, respectively. A nonzero $\mathrm{FiB}$ indicates that the reported catches are higher or lower than what should be compatible with the MTI for that year and TE of the region.

The trophic level of catches will increase, following an initial decline, if: (1) the combined effort of the fleet in a given region declines, and shifts such that the biomass of high trophic level stocks rebuilds, and becomes available to the remaining fish- 


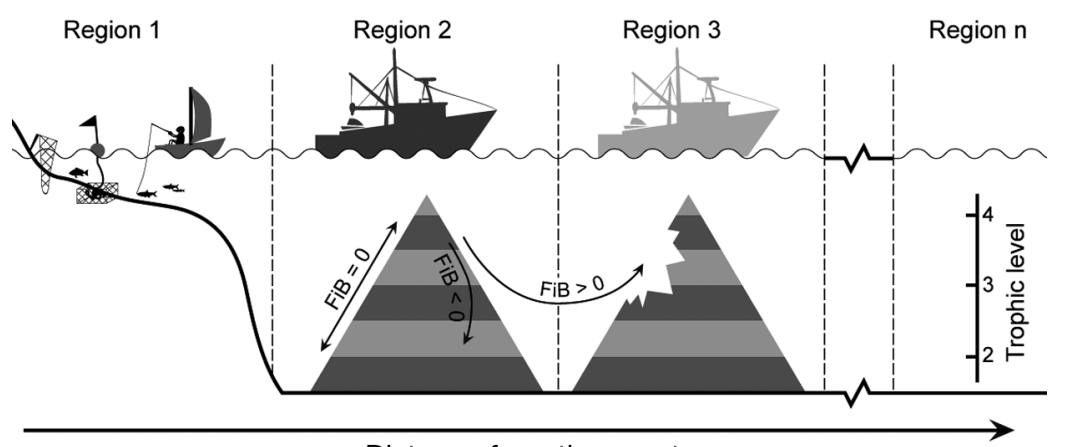

Distance from the coast

Fig. 1. Schematic representation of change in the Marine Trophic Index (MTI) and Fishing-in-Balance (FiB) index given differing modes of exploitation of coastal resources (see 'Introduction' for more details)

ery faster than the low trophic level stocks; (2) higher trophic level species migrate into the region; (3) technological improvements have been made to the fleet, which have increased the catchability of the stock; or (4) the fishing fleet expands to an adjacent area. Although the assumptions of fleet and stock stationarity are key to most fish stock assessment models (Hilborn \& Walters 1992), scenarios (3) and (4) are probable explanations for trophic level increase, especially given that there have been major advances in fleet technology and capacity (e.g. Pauly \& Chuenpagdee 2003, Stergiou \& Tsikliras 2011) and that there are multiple demonstrations that fisheries tend to expand geographically and bathymetrically (Morato et al. 2006, Swartz et al. 2010, Watson \& Morato 2013). Scenario (3) would occur, for example, if there were an ecosystem in which there was only low-intensity fishing on certain trophic levels and the fishery was not accessing the entire ecosystem. In this case, the introduction of newer, more efficient technology may provide access to higher trophic levels. If fishing stayed in the same area, fishing down would not be observed until all components of the ecosystem were being harvested. This 'technical expansion' would yield similar patterns (e.g. increasing catch and MTI) to a geographic expansion of the fishery. An example of such a pattern can be found on the west coast of Canada, which had been exploited long before the 1800s (start of data time series), but only in estuaries, rivers, and subtidal zones (Pauly et al. 2001). Here, we address the issue presented in scenario (4), where trophic levels of the catch increase due to fishing in a new location, but cannot resolve scenario (3). Overall, our aim is not to model geographic expansion, but instead to present a correction to the MTI for situations where expansion occurs.
This is schematically illustrated by Fig. 1. A the onset, near-shore smallscale fisheries operate in Region 1, generally exploiting organisms with low trophic levels (invertebrates, small fish, and the juveniles of larger species, yielding a low MTI). At some point, industrial fisheries appear, usually in deeper waters along the coast (in Region 2), and exploit both the demersal and pelagic assemblages, but usually first targeting large, high trophic level fish. This induces an increase in MTI (if it is calculated as the mean for Regions 1 and 2), due to large catches of the higher trophic level fishes being caught in Region 2, but eventually, the MTI decreases due to their higher vulnerability, relative to that of smaller, lower trophic level fishes. Increased catch of the latter species compensates for this, and FiB remains at the level to which it was set when the industrial fisheries began (e.g. at 0 ; see arrow along the left flank of the left trophic pyramid). Alternatively, if effort increases strongly without expansion out of Region 2, biomass may be so reduced that production and hence catches are affected, translating to a declining FiB (inward-turning arrow in left pyramid). Thus, declining catches in Region 2 may induce the fisheries to move into Region 3, which, given the previously untapped resources in that zone, often of higher trophic level species, will translate into increasing catch and FiB (and possibly in the MTI of the combined Regions 1, 2, and 3, depending on their relative catch levels). This process, which may involve further expansion (to $n$ regions), and completely mask the fishing-down effect in coastal zones, can be countered either by analyzing catch time series disaggregated by regions (which are often unavailable), or by using the analytical approach presented below

Viewed jointly, the MTI and FiB illustrate changes in the average trophic level over time and provide an indication of geographic expansion or contraction over the fishing region. However, it is important to recognize that both indicators are based on very basic data, i.e. reported catches and trophic levels. Therefore, some care must be taken when inferring ecosystem trends from these indices. Additionally, these indices are not always viewed and interpreted concurrently, resulting in misleading diagnoses of the status of fish stocks in an area (Branch et al. 2010). Therefore, we propose a new index called the region-based MTI (RMTI), which combines the prop- 
erties of both the original MTI and the FiB. The RMTI is capable of depicting changes in trophic level specific to distinct fishing regions over time. Moreover, unlike the $\mathrm{FiB}$, which is calculated based on an initial pair of catch and MTI over the entire time series, the RMTI is calculated from a potential range of initial MTIs based on the reported catches, which are then aggregated to detect an imbalance between the catches and mean trophic level, given a value of TE. This removes the dependence on a single initial MTI to determine a 'fishing imbalance,' pinpointing instead the times at which an expansion or contraction of the fishing fleet occurred. However, the same caveats apply to RMTI as to MTI: knowledge of the ecosystem of interest is necessary. Practitioners should implement RMTI only when it is certain that geographic expansion has occurred in order to avoid attributing instances of technological expansion in a single region to regional expansion. Finally, for each detected occurrence of imbalance, we compute a separate MTI time series for a given region.

\section{METHODS}

\section{Geographic and bathymetric expansion of fisheries}

In this contribution, we used FAO reported catches from 1950 through 2006 that were spatially disaggregated to half-degree latitude and longitude grid cells, then re-aggregated within the EEZs of each country (Watson et al. 2004). These data were previously used to demonstrate the geographic expansion of fisheries (Swartz et al. 2010). Here, geographic expansion is illustrated by computing the rate of change (positive and negative) in mean trophic level from 1985 to 2005 in $5^{\circ}$ grid cells (obtained by regrouping the catches in the above mentioned $0.5^{\circ}$ grid cells).

The effects of bathymetric expansion of the type documented by Morato et al. (2006) and Watson \& Morato (2013) were documented by exploring the relationship between the mean trophic level of the fish species in FishBase, the global encyclopedia of fishes (www.fishbase.org) and the geometric mean of their depth range, in meters.

\section{Conceptualization and definition of RMTI}

To construct the RMTI, we first define a new parameter called the 'potential catch,' which maintains a constant FiB given the reported MTI. In other words, this is the maximum possible level of catch that can be obtained when fishing is restricted to a single region under constant TE. This potential catch is derived based on the annually reported mean trophic level considering all possible values of trophic levels within the time series. When, in an annual time series of reported catches, there exists a year with a total catch that exceeds the potential catch, we consider this year to be the start of the expansion (hereafter referred to as a 'node'). For the nodal year and each subsequent year, we assume (1) that the maximum catch in the initial region is equal to the potential catch, and (2) that the difference between the potential and the reported catch is assumed to be equal to the catches taken in the new region. This is important, as it allows the resolution of the MTI in an initial region, and the definition of a new MTI time series for the new region.

Consequently, once a node is identified, the MTI in the initial region is defined as the MTI that maintains a FiB equal to 0 given the reported catches. Therefore, the MTI time series in the first region is continuous throughout the catch time series and a new MTI time series begins in the first expansion year. Consequently, we can compute an estimated MTI for the new region, using the reported MTI, the reported catches, the estimated catches for the new region, the estimated MTI in the initial region, and an assumption about the TE. This process can be repeated to detect multiple expansion periods by calculating a new potential catch for each new region.

\section{Defining the MTI and FiB}

Let $Y_{i k}$ be the reported catches in year $k$ of all species $i$ with trophic level $\mathrm{TL}_{i}$. The MTI in year $k$ is then defined as:

$$
\mathrm{MTI}_{k}=\frac{\Sigma Y_{i k} \times \mathrm{TL}_{i}}{\Sigma Y_{i k}}
$$

Given a transfer efficiency TE, we can determine the FiB index by evaluating the expression of Bhathal \& Pauly (2008):

$\mathrm{FiB}_{k}=\log _{10}\left[Y_{k}\left(\frac{1}{\mathrm{TE}}\right)^{\mathrm{MTI}_{k}}\right]-\log _{10}\left[Y_{0}\left(\frac{1}{\mathrm{TE}}\right)^{\mathrm{MTI}_{0}}\right]$

where $Y_{0}$ and $\mathrm{MTI}_{0}$ are the reported catches and mean trophic level in the initial year, respectively.

A fishery is said to be fishing in balance when $\mathrm{FiB}_{k}$ remains equal to 0 , i.e. the catch increases in a predicable fashion when the mean trophic level declines, and vice versa (illustrated by the arrow parallel to the side of the first pyramid in Fig. 1). On the other hand, when FiB >0, this implies a scenario in (1) through (4) 
in the 'Introduction', with (4) being the most likely, i.e. that the fishery has expanded geographically (as illustrated by the arrow transiting from the first to the second pyramid in Fig. 1). Thus, we shall assume that, given an initial catch $Y_{0}$ and initial mean trophic level $\mathrm{MTI}_{0}$, when:

$$
\mathrm{MTI}_{k}>\left[\mathrm{MTI}_{0}-\frac{\log _{10}\left(\frac{Y_{k}}{Y_{0}}\right)}{\log _{10}\left(\frac{1}{\mathrm{TE}}\right)}\right]
$$

the fishery is in an expansion phase.

\section{Detection of expansion in fisheries}

We define the quantity on the right hand side of the above inequality (Eq. 3) to be the MTI in the initial region $\left(\mathrm{MTI}^{*}\right)$ when $\mathrm{FiB}_{k}=0$ and given the reported catch:

$$
\mathrm{MTI}^{*}=\left[\mathrm{MTI}_{0}-\frac{\log _{10}\left(\frac{Y_{k}}{Y_{0}}\right)}{\log _{10}\left(\frac{1}{\mathrm{TE}}\right)}\right]
$$

Therefore, we assume that any reported catches $Y_{k} \neq Y_{0} \times\left(\frac{1}{\mathrm{TE}}\right)^{\mathrm{MTI}_{0}-\mathrm{MTI}_{k}}$ are indicative of an imbalance in the fishery.

Importantly, the $\mathrm{FiB}$ index relies on $\mathrm{MTI}_{0}$ actually reflecting the mean trophic levels of the species available in the (initial) fishing region. However, it is possible that the fleet at the start of the time series did not exploit the full spectrum of available species, which would result in an MTI that does not reflect the species assemblage of the ecosystem under study. This clearly was the case, e.g. in the Gulf of Thailand, where, before the onset of the trawl fishery in the early 1960s, the bulk of the catch consisted of low trophic level intertidal invertebrates (bivalves, shrimps) and trap-caught small fishes. The mean trophic level of the catch then went up for a few years as the newly introduced trawl fishery ramped up, before it strongly declined in the next 2 decades, as the trawl fishery reduced the fish and invertebrate biomass of the Gulf of Thailand to less than $5 \%$ of its original value, while profoundly altering its composition (Pauly \& Chuenpagdee 2003).

To remedy this dependence on a single initial MTI, we assume that the initial MTI can be anywhere within the range $\left[\mathrm{TL}_{\text {lower, }}, \mathrm{TL}_{\text {upper }}\right]$ where $\mathrm{TL}_{\text {lower }}$ and $\mathrm{TL}_{\text {upper }}$ are the lowest and highest reported trophic levels in the data. By partitioning the range [ $\mathrm{TL}_{\text {lower, }}$ $\mathrm{TL}_{\text {upper }}$ ] into a uniform grid of $J$ trophic levels, we can compute the maximum potential catch $\left(p Y_{k j}\right)$ per ini- tial trophic level $\left(\mathrm{TL}_{j}\right)$ where the index $j$ spans the range $\{1, \ldots J\}$ :

$$
p Y_{k j}=Y_{0} \times\left(\frac{1}{\mathrm{TE}}\right)^{\mathrm{TL}_{j}-\mathrm{MTI}_{k}}
$$

that maintains $\mathrm{FiB}_{k}=0$ for every year $k$ given the initial catch $Y_{0}$ and an initial trophic level TL $j$. We then average the $p Y_{k j}$ values for each TLj, aggregating them into a maximum potential catch per year $\left(p Y_{k}\right)$ as follows:

$$
p Y_{k}=\Sigma\left[p Y_{k j} \times \operatorname{Pr}\left(\mathrm{TL}_{j}\right)\right]
$$

where $\operatorname{Pr}\left(\mathrm{TL}_{j}\right)$ is the probability that $\mathrm{MTI}_{0}=\mathrm{TL}_{j}$. Here, we use a uniform probability distribution, thus the $p Y_{k}$ is just the average of $p Y_{k j}$. However, if additional knowledge is available about the structure of the distribution of trophic levels in a given ecosystem, one could apply that probability distribution. The term $p Y_{k}$ reflects the expected value of the maximum potential catch that a fishing fleet should be able to extract from a single fishing region, given the TE. The expectation is evaluated over the probability distribution of initial trophic levels.

The potential catch $p Y_{k}$ is also independent of the initial year's MTI, thus providing an indicator for the balance of the fishery irrespective of the stationarity of the fleet or the stocks. So long as the reported catches $Y_{k}$ are smaller than $p Y_{k}$ it is unlikely that the fishing fleet has expanded into a new fishing region. On the other hand, if the reported catches $Y_{k}$ exceed the potential catch $p Y_{k}$, then the year indexed by $k$ is likely to be an expansion year or node, indexed by $n_{r}$ where $r$ refers to each new region identified. Consequently, the reported MTI for every year that follows the node no longer represents the same fishing region, but is now skewed by the catches from the region into which the fleet has expanded. In what follows, we assume that $Y_{k}>p Y_{k}$ and demonstrate how to estimate an RMTI for each individual region.

\section{Estimation of RMTIs}

The detection of the nodes that mark years of expansion allows us to recalculate the corresponding MTIs for every expansion region separately. Our estimation is based on 2 assumptions: (1) that the fish stocks in the initial region continue to be fished following the year of expansion, and (2) that fishing in the initial region continues to be in balance or contracting given the TE of that region.

We define the node of an expansion region $(r)$ as the year prior to which the potential catch becomes larger than the reported catch, i.e. 


$$
n_{r}=k \text {, such that } p Y_{k-1}>Y_{k-1} \text { and } p Y_{k} \leq Y_{k}
$$

To estimate the catches $\left(\hat{Y}_{k}^{r}\right)$ and associated MTIs $\left(\widehat{\mathrm{MTI}}_{k}^{r}\right)$ for all expansion regions $(r)$ in the years $(k)$ that follow the node $\left(n_{r}\right)$, we start by estimating the catches $\left(\hat{Y}_{k}^{1}\right)$ from the first region by computing the maximum potential catch, initialized by the reported catches $Y_{n_{1}}$ and mean trophic level $\mathrm{MTI}_{n_{1}}$ at the node. In other words, we set $\mathrm{FiB}=0$ and use the reported MTI $\left(\mathrm{MTI}_{k}\right)$ to solve for $\hat{Y}_{k}^{1}$. Hence, we have:

$$
\hat{Y}_{k}^{1}=Y_{n_{i}} \times\left(\frac{1}{\mathrm{TE}}\right)^{\mathrm{MTI}_{n_{1}}-\mathrm{MTI}_{k}} \text { for } k>n_{1}
$$

We then assign the difference between the reported catches $Y_{k}$ in every year $k$ following the node and the estimated $\left(\hat{Y}_{k}^{1}\right)$ to be the catches from the new fishing region:

$$
\hat{Y}_{k}^{r}=Y_{k}-\left(\hat{Y}_{k}^{1}+\ldots+\hat{Y}_{k}^{r-1}\right) \text { for } n_{r-1}<k<n_{r}
$$

Next, we estimate the mean trophic level in the initial region $\left(\widehat{\mathrm{MTI}}_{k}^{1}\right)$ initialized at the node by also setting $\mathrm{FiB}=0$ and using the reported catch $\left(Y_{k}\right)$, yielding:

$$
\widehat{\operatorname{MTI}}_{k}^{1}=\left[M T I_{n_{1}}-\frac{\log _{10}\left(\frac{Y_{k}}{Y_{n_{1}}}\right)}{\log _{10}\left(\frac{1}{\mathrm{TE}}\right)}\right]
$$

The effect of assigning $\hat{Y}_{k}^{1}$ and $\left(\widehat{\mathrm{MTI}}_{k}^{1}\right)$ to the first region ensures that the resulting $\mathrm{FiB}$ will remain $\leq 0$ in all years after the node, thereby excluding any further expansion in that region. Additionally, the estimated MTI is predisposed to decrease in the first region after the node. This assumption is likely justified because of the fact that it will usually be more profitable to fish inshore due to lower transit time and costs (e.g. fuel). Based on this assumption, one would expect that the catch per unit effort (CPUE) nearer to the coast would be lower and that, unless inshore fisheries are allowed to rebuild, the mean trophic level would continue to decline. 'Gravity models' (Caddy 1975, Walters \& Bonfil 1999, Gelchu \& Pauly 2007, Watson et al. 2013), which account for the distribution of CPUE given the cost of fishing, illustrate this concept nicely.

Finally, we estimate the MTI in the second region $\left(\widehat{\mathrm{MTI}}_{k}^{2}\right)$, noting from the definition of MTI that:

$$
\begin{aligned}
\operatorname{MTI}_{k} \times Y_{k} & =\Sigma_{i} Y_{i k} \times \mathrm{TL}_{i} \\
& =\Sigma_{i \in R_{1}} Y_{i k} \times \mathrm{TL}_{i}+\Sigma_{i \in R_{2}} Y_{j k} \times \mathrm{TL}_{j} \\
& =\widehat{\operatorname{MTI}}_{k}^{1} \times \hat{Y}_{k}^{1}+\widehat{\operatorname{MTI}}_{k}^{2} \times \hat{Y}_{k}^{2}
\end{aligned}
$$

where $\epsilon$ indicates an element in a set of indices, and $R_{1}$ and $R_{2}$ are the sets of indices belonging to Regions 1 and 2, respectively. From the above equality, we can see that the MTI to be estimated in Region 2 is given by:

$$
\widehat{\mathrm{MTI}}_{k}^{2}=\frac{\mathrm{MTI}_{k} \times Y_{k}-\widehat{\mathrm{MTI}}_{k}^{1} \times \hat{Y}_{k}^{1}}{\hat{Y}_{k}^{2}}
$$

We then proceed with the same methodology comparing $\hat{Y}_{k}^{2}$ with $p Y_{k}$ to detect subsequent nodes.

An important feature of the method is that when catches and MTI in the second or subsequent region decrease simultaneously, we assume that there is a contraction in the fishery and we do not continue to assign MTI values in the newly identified region. This results in a break in the RMTI in the new region until the reported catch again exceeds the potential catch. This is a conservative feature of the RMTI in that we try to maintain the lowest number of regions that explain the data.

Our framework stems from the premise that fishing in a new region, after the identification of a node year, represents full exploitation of all trophic levels in the ecosystem. Therefore, for every year following the node year, there can only be fishing down happening in the first region. Hence, the $\mathrm{FiB}$ in the first region following the node year should be $\leq 0$. Ideally, we would like to maintain a $\mathrm{FiB}=0$ in the first region after the node. However, solving for both catch and MTI while setting $\mathrm{FiB}=0$ (Eq. 2) is an ill-posed problem since we would need to solve for 2 unknowns and we do not possess additional information relating the catch and MTI in the first region. Therefore, we opt for the relaxed condition of $\mathrm{FiB} \leq 0$, which our framework achieves.

\section{Testing the approach}

To test this approach, we generated a catch and associated MTI time series for 2 independent regions, each with a decreasing MTI and increasing catch, such that $\mathrm{FiB} \leq 0$ in each region separately (i.e. no expansion within each region). In the first region, we assumed that fishing commenced at Year 1 and was continuous for $150 \mathrm{yr}$. Fishing in the second region was assumed to occur from Year 50 to Year 150. The MTI time series was computed as the decreasing limb of a cosine function with random normal variability. In both regions, catch was generated from Eq. (5) with $\mathrm{TL}_{j}=\mathrm{MTI}_{0}$ and the addition of random, normal variability. Initial catch $\left(Y_{0}\right)$ was set to 5000 arbitrary units. Based on these time series, we com- 

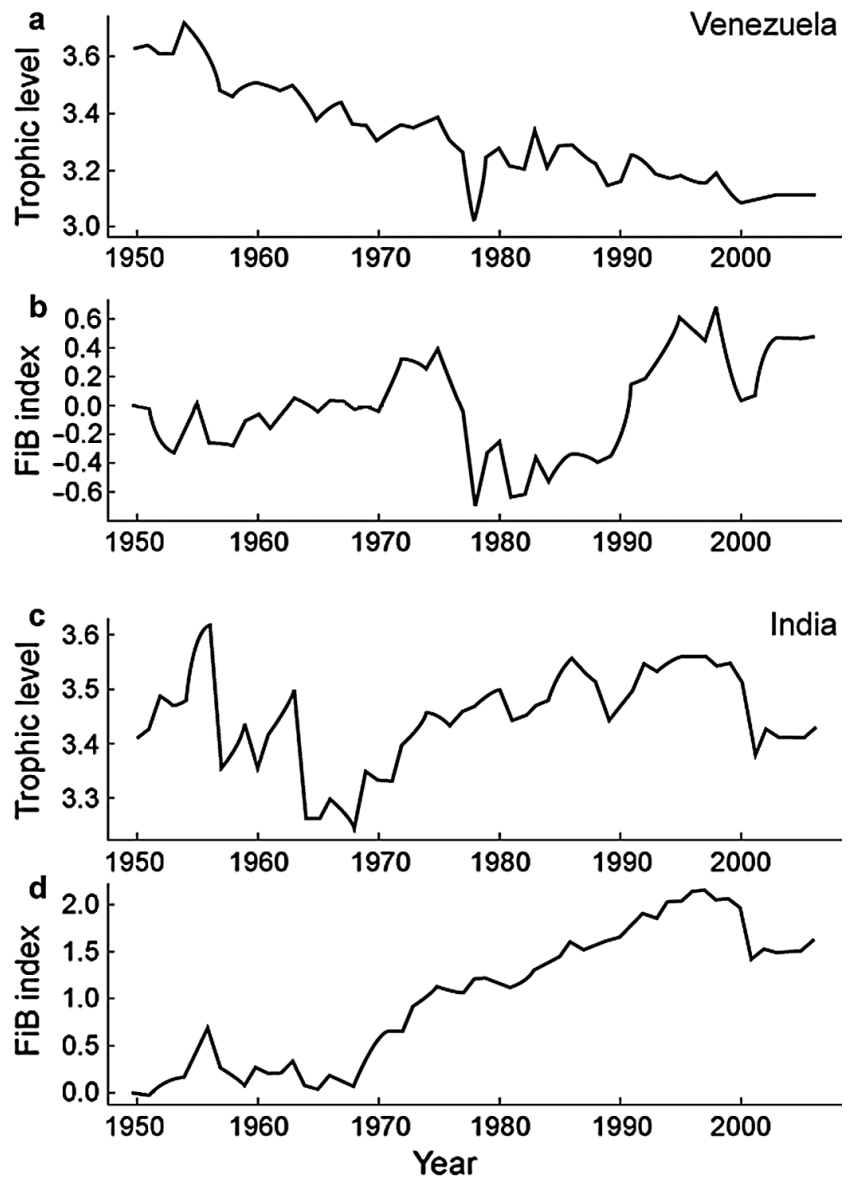

Fig. 2. Time series of mean trophic level (Marine Trophic Index, MTI) and the Fishing-in-Balance (FiB) index for $(a, b)$ Venezuela and $(\mathrm{c}, \mathrm{d})$ India. The panels for Venezuela illustrate an MTI that continuously decreases while the FiB remains relatively constant. The panels for India illustrate an MTI that declines, then increases, associated with a sharply increasing FiB when MTI increases, suggestive of expansion, as described by Bhathal \& Pauly (2008)

puted the 'reported' catch as the sum of the catch in the 2 regions, with the 'reported' MTI directly following from Eq. (12). We used a uniform distribution of trophic levels in the estimation of $p Y_{k}$. We tested a base case run with TEs of $10 \%$ in each region, and also explored the effect of using TE values of 5 and $15 \%$.

Finally, we applied the method to real catch data for all EEZs globally. We present the results in terms of overall trends in the RMTI in each of the first 3 defined regions (if applicable) for the 50 EEZs with the largest contribution to global catches. In addition, we examined 2 countries with very different patterns in FiB and MTI, viz. India and Venezuela (Fig. 2). In Venezuela, MTI continuously decreases, but FiB fluctuates around 0 , indicative of a potential 'real' decline in MTI. In contrast, in India, the FiB is stable until the late 1960s, after which it strongly increases. This occurs in conjunction with a time series of MTI that declines through the late 1960s and then increases. Examination of the FiB and MTI together, in this case, suggest expansion, which is masking a potential decline in MTI.

\section{RESULTS}

Fig. 3 illustrates the slope of the mean trophic level over the period 1985 to 2005 in sequential spatial regions from the coast. If we assume that fishing began historically along the coast, then we see declines in mean trophic level in mid-latitude regions of the Northern Hemisphere that had been industrially fished for decades, and increasing trophic levels in newly accessed offshore regions, mainly in high and southern latitudes. In these offshore regions, we expect higher trophic level species to be fished, i.e. large tunas, billfish, and other large pelagic species. In the tropics, which are dominated by small-scale fisheries, we do not see the same declines in mean trophic level either in the nearshore or offshore regions. This is likely because the taxonomic resolution of the catch from the tropics is generally very poor for lower trophic level species while tunas are a well-represented and growing component of the catches from this region (Pauly \& Palomares 2005, Kleisner et al. 2013b). Bathymetric expansion of fisheries is also important, given that we found a significant linear relationship $(p<0.05)$ between mean trophic level and the geometric mean depth range of fishes $(D$, in $\mathrm{m})$, i.e. mean trophic level $=2.91+$ 0.33( $\left.\log _{10} D\right)$, based on 3765 marine fish species with both depth range and trophic level in FishBase (see www.fishbase.org).

The results of our simulations to test the RMTI are presented in Figs. 4-7. Fig. 4 illustrates the relationship between the potential catch and the reported catch, over a time series of $50 \mathrm{yr}$ for the first region and $100 \mathrm{yr}$ in the second region. The RMTI correctly identifies the year of expansion as Year 50.

Next, we show that, with an assumed TE of $10 \%$ in both regions, the RMTI significantly improves our ability to determine the true MTI in each region when compared to the reported MTI calculated for a single region (Fig. 5). In this scenario, relative to the reported MTI, the average root mean squared error (RMSE) was $53 \%$ lower for Region 1 and $38 \%$ lower for Region 2 (Table 1). We also explored the ability of the model to perform when the model assumes 


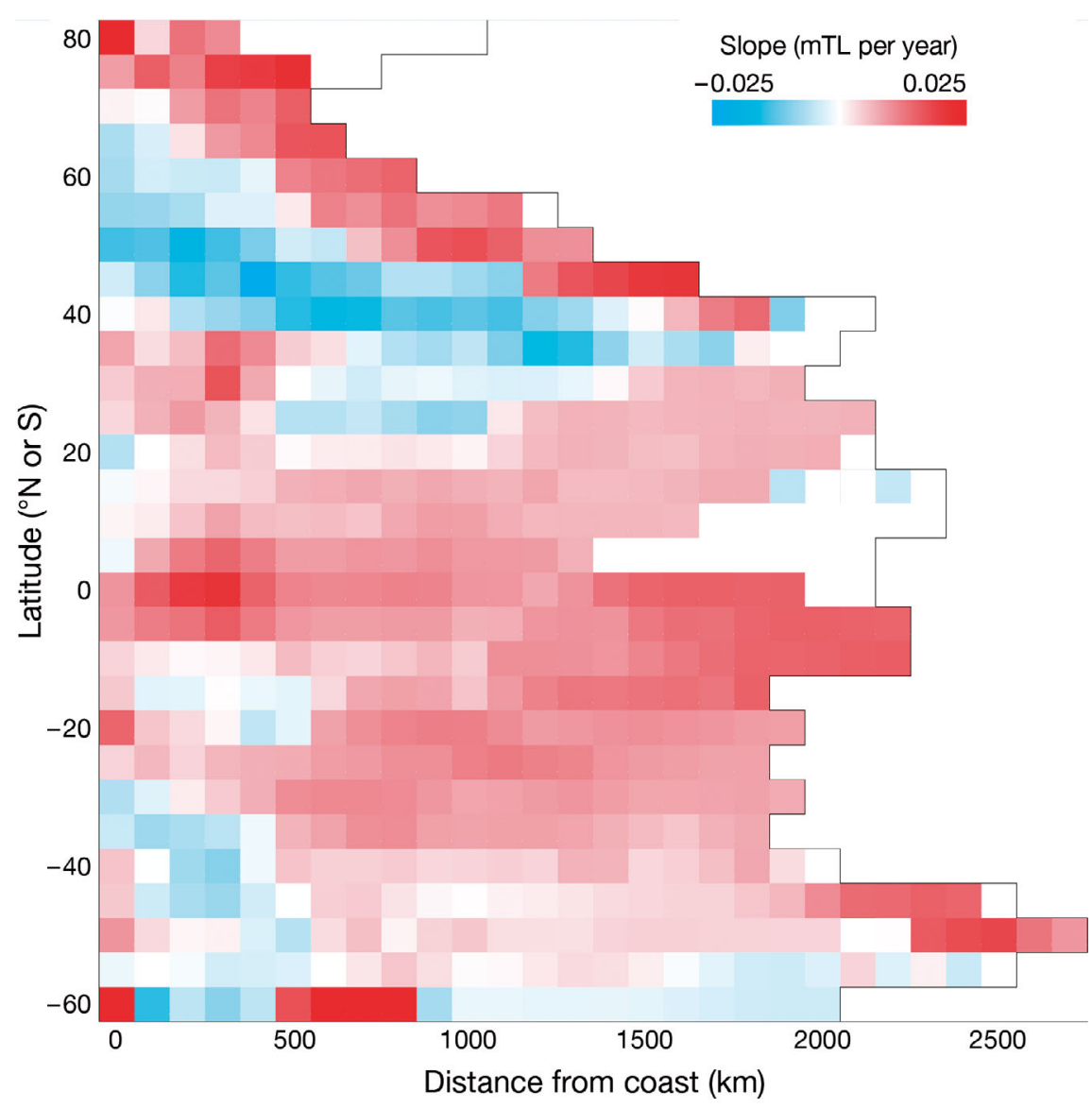

Fig. 3. Average slope of mean trophic level (mTL) from 1985 to 2005 by latitude ( $y$-axis) and distance from the coast ( $x$-axis). Slopes were estimated individually for each grid cell and tested for statistical significance (alpha levels $>-0.025$ and $<0.025$ ). The regions in blue (red) denote areas where slopes are significantly negative (positive) and mTL decreased (increased) over the $21 \mathrm{yr}$ period. Note that mTL in the traditional industrial fishing grounds of North Atlantic and Northwest Pacific continental shelves continued to decline while the increases in mTL occurred at low latitude and in offshore regions, reflecting what is known of the global expansion of fisheries (Swartz et al. 2010)

$10 \% \mathrm{TE}$ and the true TE is lower (Fig. 6). In this case, viz. overestimation of the TE, the recovery of the MTI is improved by $69 \%$ and $45 \%$ for Regions 1 and 2, respectively (Table 1). This seemingly strange result is a function of the fact that the resulting $\mathrm{FiB}$ in the first region after the node is $\leq 0$. Therefore, an overestimation of the TE pushes the resulting $\mathrm{FiB}$ closer to 0 . In the case where the model uses a TE that is underestimated, we find that, while the decrease in RMSE is less than with an exact or an overestimated TE, the model still improves on the ability to detect the true MTI in each region (Fig. 7). There is a $31 \%$ and $28 \%$ reduction in RMSE in each region, respectively (Table 1).
We also tested the effect of having a gradual increase in catch in the second region (as opposed to the 'jump' in Fig. 4 in Year 50). In this case, although the true node year is Year 50, the method identifies Year 91 as the node year, where the reported catch exceeds the potential catch (Fig. 8). Therefore, Region 2 is only detected in Year 91, and a new MTI and catch time series are calculated for the detected region (Fig. 9). Similar to the previous example illustrated in Figs. 4 \& 5, the estimated MTI and catch time series for both regions provide a better fit to the true data. Moreover, a simulation over 10000 iterations shows that the RMSE between the estimated MTI and the true MTI reduces to 0.91 in the first region and 1.69 in the second region for 1.45 and 1.79 , respectively, for the reported MTI. We also tested the 'Sequential Regime Shift Detection' algorithm (version 3.2) in Excel (Rodionov 2005) in order to test whether such an algorithm might be better able to identify the correct node year. Using the default parameter values (e.g. a significance level of 0.1, a cut-off length of 10, and a Huber's weight parameter of 1) we first applied the regime shift algorithm to the MTI and catch dataset used to generate Figs. 4 \& 5 (i.e. catch with a more abrupt increase in the node year). To be classified as a node year using the regime shift algorithm, both the MTI and the catch time series must exhibit a regime shift in the same year. The regime shift algorithm identified a node in Year 51. We also applied Rodionov's method to the dataset used to generate Figs. 8 \& 9 (i.e. catch with a gradual increase through the node year). In this case, a regime shift was detected in Year 93.

Trends for the 50 EEZs that contribute most to global catches are presented in Table 2 . Here, we focus on 2 countries: (1) India, a country that is the fifth largest contributor to global catches and (2) Venezuela, a country with relatively low contributions to global catches. We use these examples to illustrate the ability of the RMTI to detect new regions.

For India, a country for which a geographic expansion within the EEZ has been established (Bhathal \& Pauly 2008), our method generates 3 distinct time 


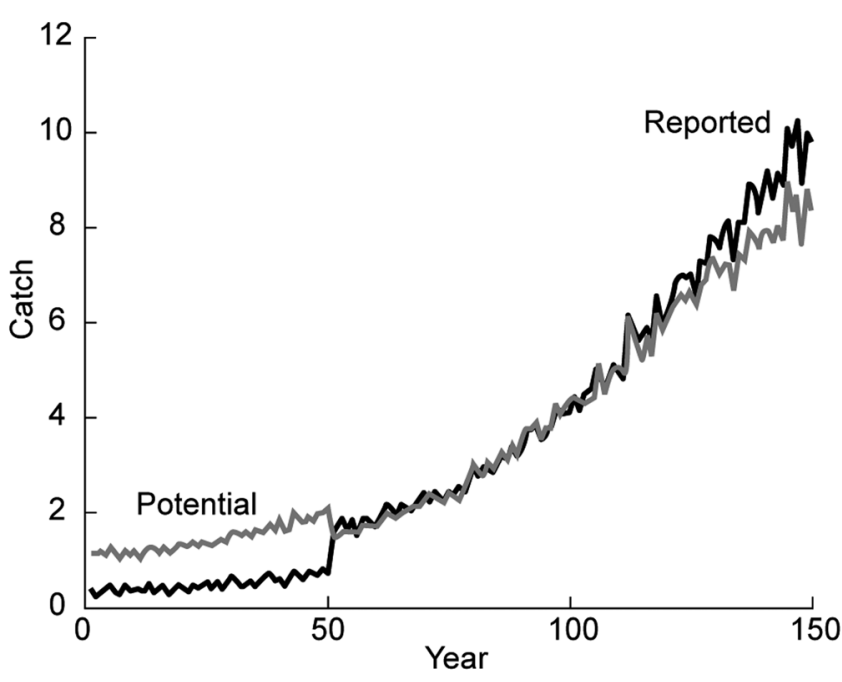

Fig. 4. Time series of reported and potential catch (arbitrary units) based on simulated data, illustrating the ability of the algorithm to detect the correct year (50) of expansion. The year of expansion is determined as the year when the reported catches exceed the potential catches

series of mean trophic levels, corresponding to 3 successive regions likely to be parallel along the coast (Fig. 10). The first region (Fig. 10d, lower line, corresponding to the nearshore region), documents a fairly significant decline in trophic levels (from approximately 3.5 to 3.0 ), which is not apparent in the original MTI, based on the total catch time series (Fig. 10c). In 1970, a second time series appears in a second region, which reflects strong increases in
Table 1. RMSEs for estimation of the true Marine Trophic Index (MTI) in each region over 10000 iterations. In all cases, the estimated MTI has a lower error than the reported MTI. The error reduction is lowest when the transfer efficiency (TE) is overestimated. For the overestimated TE, $10 \%$ was assumed instead of the 'true' $8 \%$ (in Region 1) and 5\% (in Region 2) values; for the underestimated TE, $10 \%$ was assumed instead of the 'true' $12 \%$ (in Region 1) and 15\% (in Region 2) values

\begin{tabular}{|lcccc|}
\hline TE estimation & \multicolumn{2}{c}{$\begin{array}{c}\text { Region 1 } \\
\text { Estimated Reported }\end{array}$} & \multicolumn{2}{c|}{$\begin{array}{c}\text { Region 2 } \\
\text { Estimated Reported }\end{array}$} \\
\hline Exact (TE $=10 \%)$ & 0.828 & 1.756 & 1.527 & 2.477 \\
Overestimated & 0.558 & 1.799 & 1.343 & 2.448 \\
Underestimated & 1.225 & 1.772 & 1.763 & 2.459 \\
\hline
\end{tabular}

catches and an increasing FiB. A third region is identified beginning in 1980, associated with a weaker decline in trophic levels, presumably due to the absence, at the edge of the EEZ, of exploitable stocks of low trophic level fishes. These expansions correspond to the promotion of 'deep-sea fishing' in India's successive Five Year Plans (ICAR 1998, Bhathal 2005). Indeed, each subsequent trend is of a higher average trophic level, indicating that fishing in the new (offshore) regions is based on higher trophic level fish such as tunas, sharks, and billfish.

The RMTI is very different for Venezuela (Fig. 11), which has a rather narrow shelf, and whose demersal fisheries were quickly developed. In this case, catches were increasing through the 1960s and early 1970s, and a new region was detected in the 1960s. However, in the late 1970s, catches began to
Fig. 5. Time series of $(a, b)$ Marine Trophic Index (MTI) and (c,d) catch (arbitrary units) based on data simulated for 2 regions assuming a constant $10 \%$ transfer efficiency in both regions. Fishing in Region 1 begins in Year 0 and continues through Year 150 and fishing in Region 2 begins in Year 50 and continues through Year 150. Notice that the reported catch and MTI is a single time series for both regions. Both the estimated and the true catches in Regions 1 and 2 sum to the reported catch. By estimating the catch and the MTI in each region separately, we are able to obtain more accurate catch and MTI time series in each region (i.e. closer to the 'true' values)
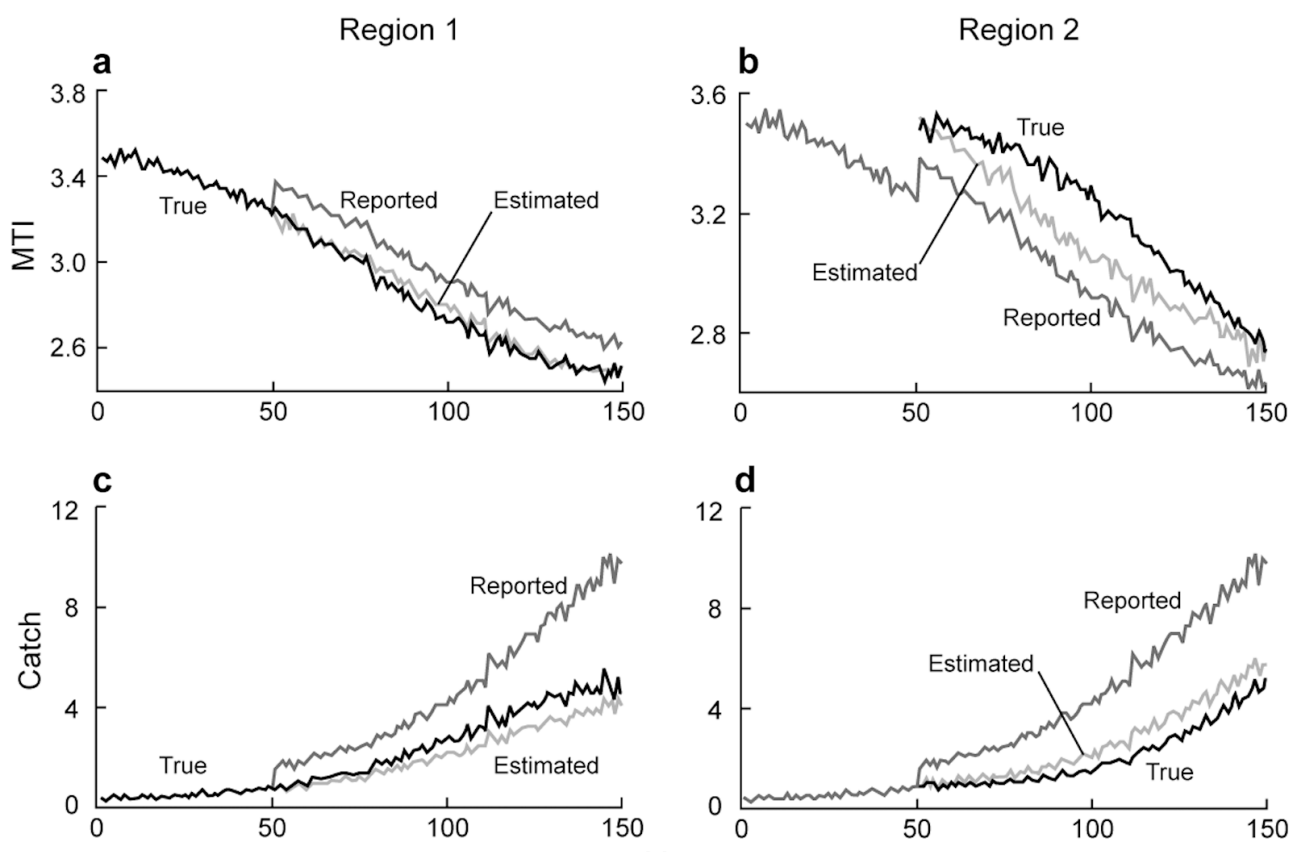

d

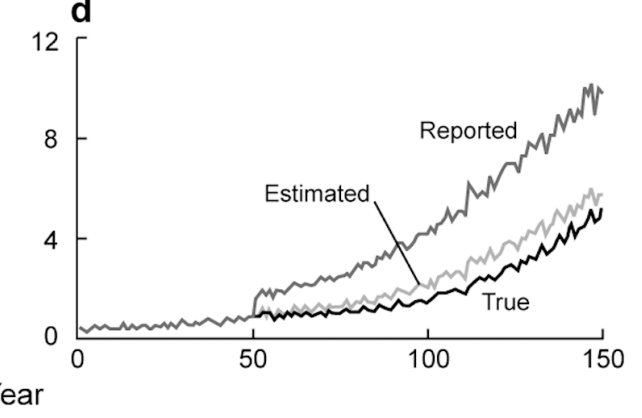


Region 1
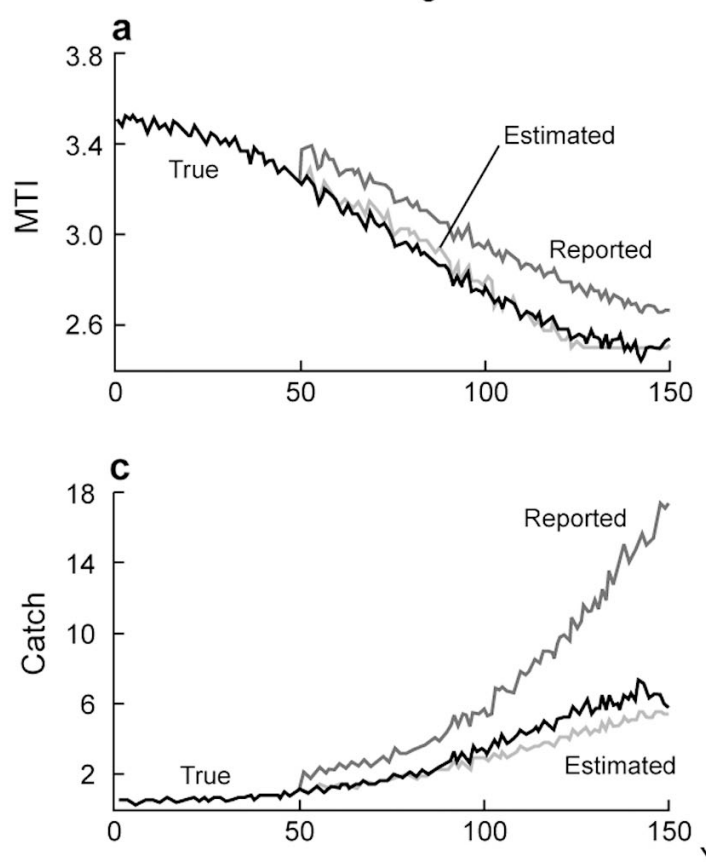

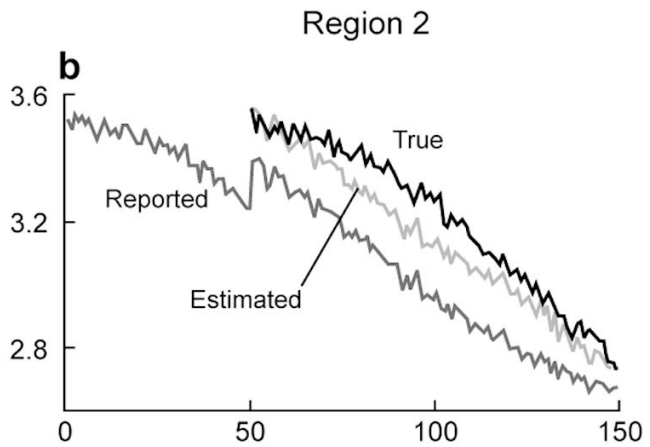

d

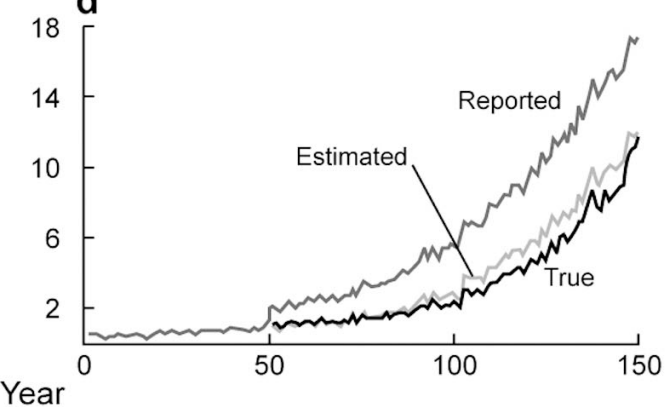

Fig. 6. Time series of $(a, b)$ Marine Trophic Index (MTI) and (c,d) catch (arbitrary units) based on data simulated for 2 regions with $8 \%$ and $5 \%$ transfer efficiencies, respectively. The model assumes $10 \%$ transfer efficiency, and all other parameters are as defined for Fig. 4. This illustrates the model performance when the real transfer efficiency is overestimated decline and the RMTI for the second period has a 'break,' indicating a retraction period. The method indicates that fishing in the second region re-commenced in the 1980s, corresponding to the year in which many countries in Central and South America, including Venezuela, entered the large-scale industrial fisheries, mostly with purse seiners (Mendoza et al. 2010).

\section{DISCUSSION}

In response to the original presentation of the 'fishing down' concept (Pauly et al. 1998a), Caddy et al. (1998), while accepting that the concept held for the cases for which it was demonstrated, challenged its generality. This challenge was based on problems they assumed would be caused by (1) the lack of
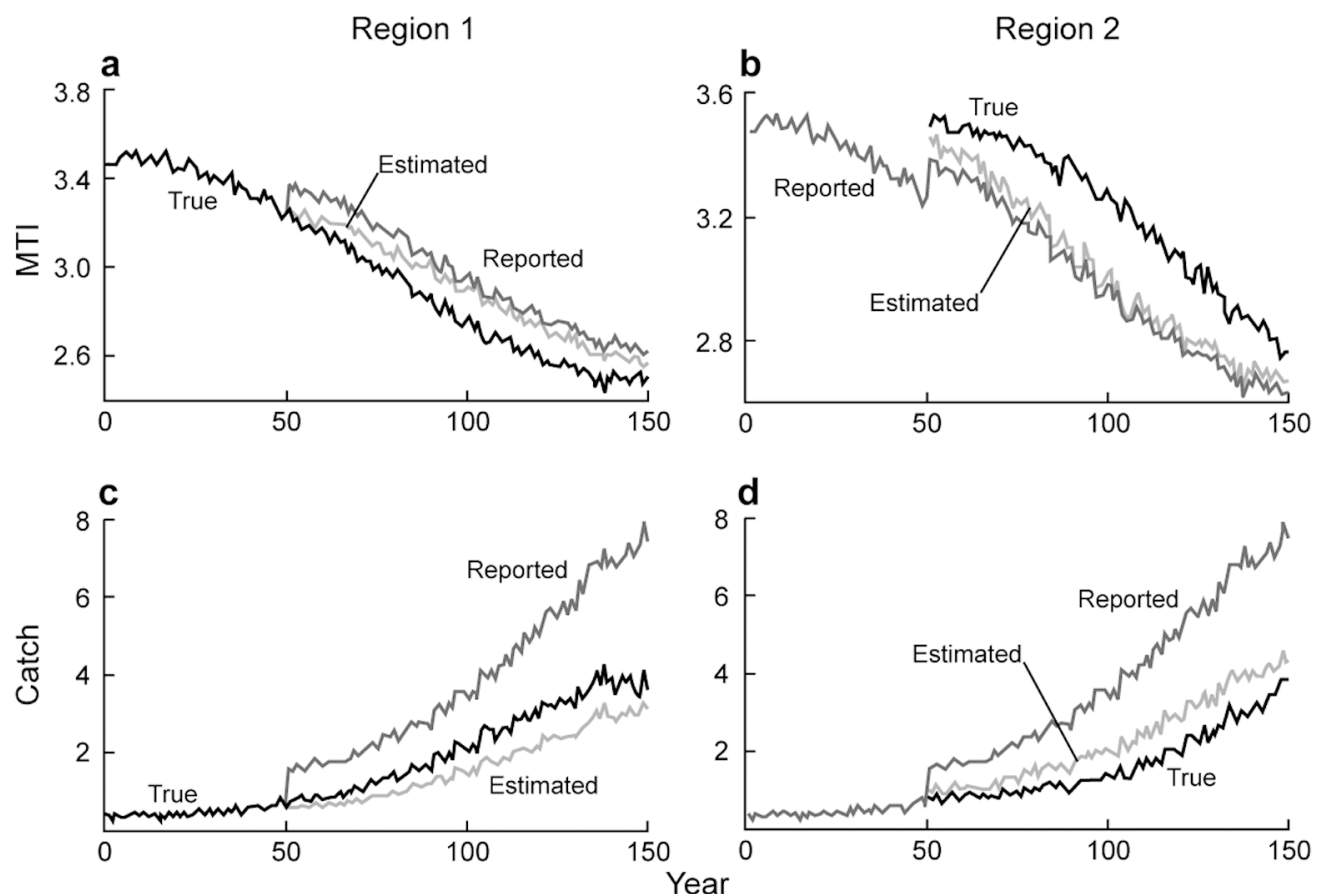

Fig. 7. Time series of $(a, b)$ Marine Trophic Index (MTI) and $(\mathrm{c}, \mathrm{d})$ catch (arbitrary units) based on data simulated for 2 regions with $12 \%$ and $15 \%$ transfer efficiencies, respectively. The model assumes $10 \%$ transfer efficiency, and all other parameters are as defined for Fig. 4. This illustrates the model performance when the real transfer efficiency is underestimated 


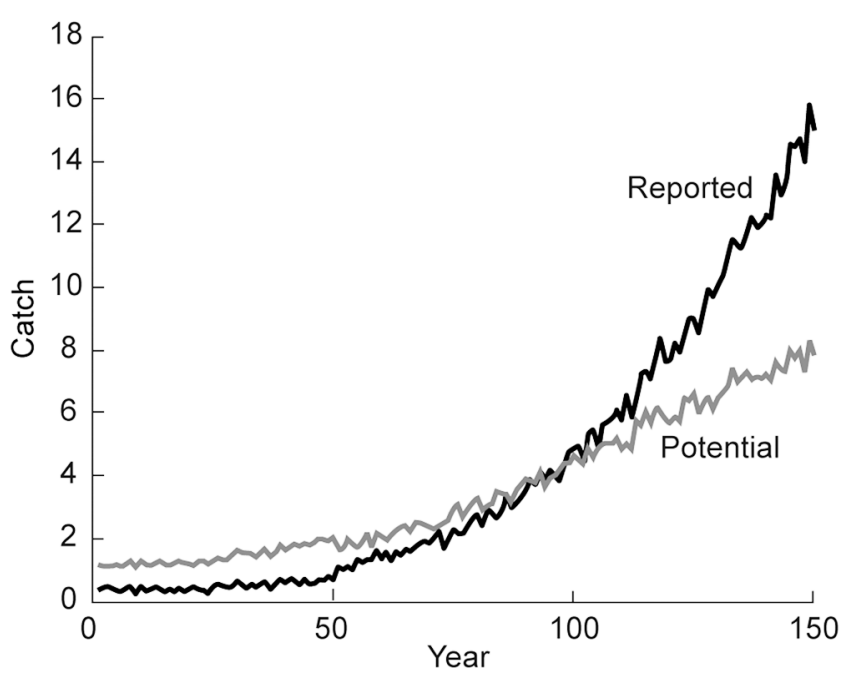

Fig. 8. Time series of reported and potential catch (arbitrary units) based on simulated data with a second region beginning in Year 50. In this case, the catch increases gradually and the node year (i.e. the year in which the reported catch exceeds the potential catch) is not identified until Year 91

taxonomic resolution in the FAO data; (2) the use of landings data as an ecosystem indicator; (3) aquaculture development; and (4) 'bottom up' effects such as eutrophication.
These problems were easily dealt with, and in all 4 cases, their resolution actually reinforced the original arguments (Pauly et al. 1998b, Pauly \& Palomares 2005, Pauly 2010). In the process, however, the issue of geographic over-aggregation of catch data emerged as the most serious impediment to the generalized use of what had become, in the meantime, the MTI (Pauly \& Watson 2005).

Various efforts were undertaken to address geographic over-aggregation; one of them was the development of the FiB index (Pauly et al. 2000b), which can be interpreted as a fisheries expansion index (Bhathal \& Pauly 2008), and which must be taken into account when attempting to interpret time series of MTI. However, as exemplified by Branch et al. (2010), it is difficult to visually interpret the interactions of 2 time series, and an alternative index was sought, which would combine the key features of the MTI with those of the FiB index. A first result was the 'Corrected Trophic Index' of Kleisner \& Pauly (2011), which sought to correct the original MTI for geographic expansion, but still operated under the assumption that the trophic index applied to a single, aggregated region. Here we have shown that the RMTI improves upon this
Fig. 9. Time series of $(a, b)$ Marine Trophic Index (MTI) and (c,d) catch (arbitrary units) based on data simulated for 2 regions assuming a constant $10 \%$ transfer efficiency in both regions. Fishing in Region 1 begins in Year 0 and continues through Year 150, and fishing in Region 2 begins in Year 50 and continues through Year 150. In this case, the gradual increase in catch results in a late detection of the node year, but the estimated MTI and catch time series provide a better fit after the node year than the reported catch
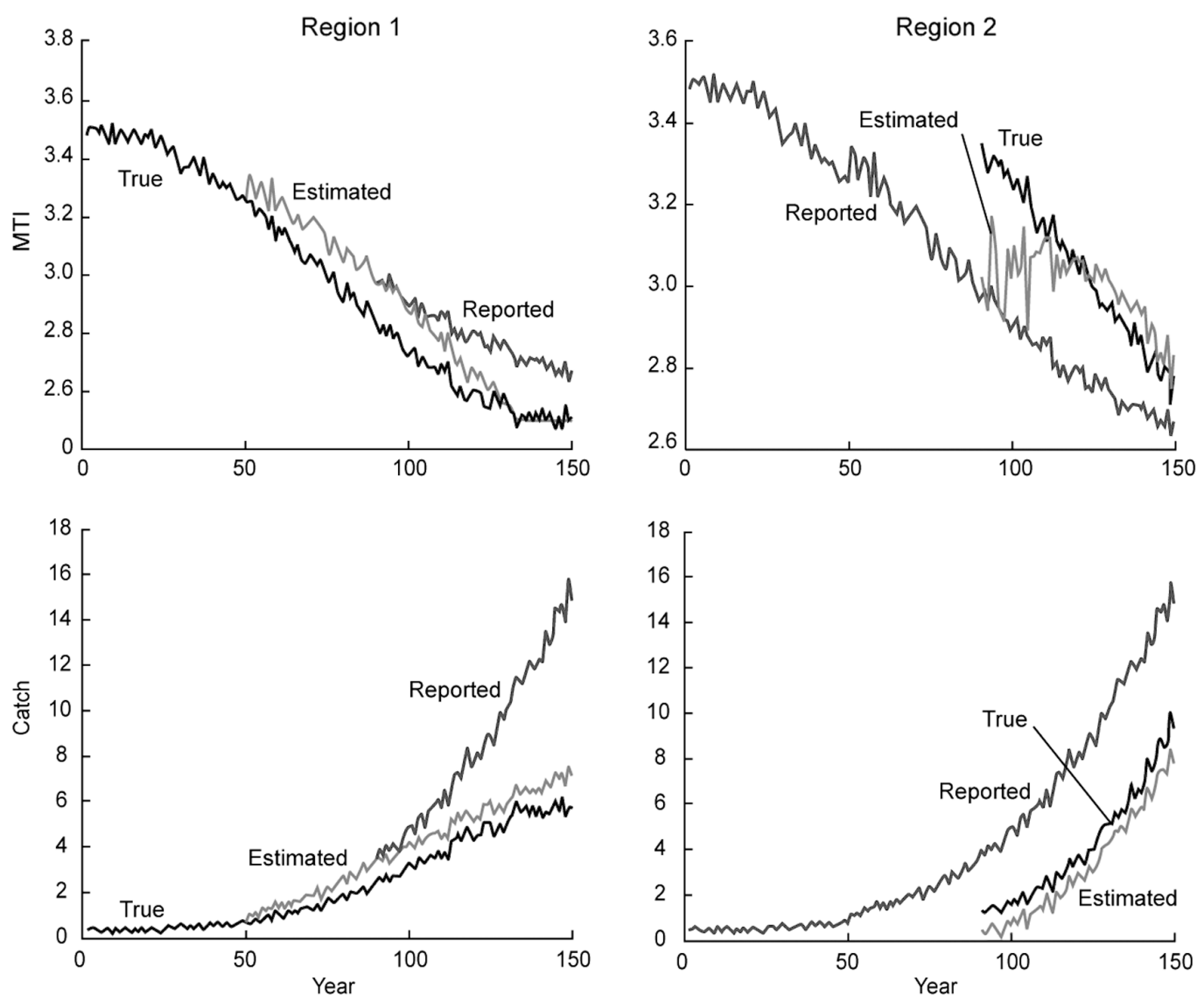
Table 2. Slope directions of the region-based Marine Trophic Index (RMTI) of 50 exclusive economic zones (EEZs) with the largest contribution to global catch. For each country, the start year is 1950 . For Regions 2 and 3, the node year is also listed

\begin{tabular}{|c|c|c|c|c|c|}
\hline \multirow{2}{*}{$\begin{array}{l}\text { EEZ } \\
\text { China }\end{array}$} & \multirow{2}{*}{$\begin{array}{c}\text { Region } 1 \\
\text { Direction } \\
y\end{array}$} & \multicolumn{2}{|c|}{$\begin{array}{c}\text { Region } 2 \\
\text { Year Direction }\end{array}$} & \multicolumn{2}{|c|}{$\begin{array}{c}\text { Region } 3 \\
\text { Year Direction }\end{array}$} \\
\hline & & & & & \\
\hline Peru & y & 1956 & $y$ & & \\
\hline Russia (Pacific) & ע & 1962 & $\pi$ & 1968 & $\rightarrow$ \\
\hline Chile & y & & & & \\
\hline India (Mainland) & y & 1968 & y & 1973 & $\rightarrow$ \\
\hline Vietnam & $\rightarrow$ & & & & \\
\hline Norway & y & 1964 & $\rightarrow$ & & \\
\hline USA (Alaska) & y & 1959 & y & 1981 & $\rightarrow$ \\
\hline Indonesia (Western) & y & & & & \\
\hline Taiwan & $\rightarrow$ & & & & \\
\hline UK & y & 1963 & $\rightarrow$ & & \\
\hline Japan (Main islands) & y & 1961 & $\pi$ & 1976 & $\rightarrow$ \\
\hline Indonesia (Eastern) & y & 1968 & y & 1976 & $\rightarrow$ \\
\hline Philippines & $\rightarrow$ & & & & \\
\hline Iceland & $\mathbf{y}$ & 1978 & $\rightarrow$ & & \\
\hline Japan (Outer islands) & y & 1954 & $\mathbf{y}$ & 1977 & $\rightarrow$ \\
\hline USA (East coast \& Gulf of Mexico) & o) y & & & & \\
\hline Korea (South) & y & 1969 & y & 1988 & $\Rightarrow$ \\
\hline Myanmar & $\rightarrow$ & & & & \\
\hline Argentina & y & 1962 & y & 1972 & $y$ \\
\hline Canada & $\bar{y}$ & & & & \\
\hline Mexico & y & 1961 & y & 1966 & y \\
\hline Morocco & y & 1950 & y & 1958 & y \\
\hline India (Andaman \& Nicobar Isl.) & $\rightarrow$ & & & & \\
\hline South Africa & y & 1964 & $\rightarrow$ & & \\
\hline Ireland & y & 1970 & y & 1984 & $\rightarrow$ \\
\hline Thailand & y & 1962 & $\pi$ & & \\
\hline Morocco (Western Sahara) & y & 1961 & y & 1966 & y \\
\hline Malaysia (East peninsula) & y & 1960 & y & 1964 & $\rightarrow$ \\
\hline Denmark & $\rightarrow$ & 1961 & $\rightarrow$ & & \\
\hline New Zealand & y & 1971 & $\pi$ & & \\
\hline Denmark (Faeroe Isl.) & $\rightarrow$ & & & & \\
\hline USA (West coast) & $y$ & 1982 & $\pi$ & & \\
\hline Namibia & $\rightarrow$ & 1967 & $\pi$ & 1971 & $\pi$ \\
\hline Senegal & y & 1956 & y & 1960 & $y$ \\
\hline Malaysia (West peninsula) & $y$ & 1958 & $\bar{y}$ & 1974 & $\rightarrow$ \\
\hline Malaysia (Sarawak) & $\bar{y}$ & 2000 & $\rightarrow$ & & \\
\hline Sweden & $\bar{y}$ & 1954 & $\pi$ & 1965 & $\rightarrow$ \\
\hline Spain & $y$ & 1958 & $\rightarrow$ & & \\
\hline Bangladesh & $y$ & & & & \\
\hline France & $\rightarrow$ & 1983 & $\rightarrow$ & & \\
\hline Denmark (Greenland) & $y$ & & & & \\
\hline Mauritania & y & 1958 & $\rightarrow$ & & \\
\hline Russia (Barents Sea) & y & & & & \\
\hline Malaysia (Sabah) & $\rightarrow$ & & & & \\
\hline Brazil & y & 1960 & y & 1964 & $\rightarrow$ \\
\hline Germany & $\rightarrow$ & 1962 & $\rightarrow$ & & \\
\hline Netherlands & $\rightarrow$ & 1964 & $\rightarrow$ & & \\
\hline Turkey (Black Sea) & y & 1964 & $y$ & 1978 & $\rightarrow$ \\
\hline Korea (North) & $\rightarrow$ & & & & \\
\hline
\end{tabular}

work by providing separate indices for each detected expansion region.

Although less straightforward to compute than the original MTI, the RMTI has the key advantage over its predecessor in that it is less susceptible to biasing by geographic expansion of the fisheries. (Note that the R-code for running the RMTI and sample data are available at www.seaaroundus. org/data/rmti/). Additionally, it explicitly accounts for such expansion by producing time series of mean trophic level for different periods and regions, documenting both the occurrence and the impact of geographic expansion on the trophic structure of marine ecosystems. Also, and most importantly, in regions where there is no expansion, or where there is possibly a contraction of the fisheries, the RMTI for that region shows a break in the time series. Thus, the RMTI does not generate 'fishing down' where it does not occur.

However, there are several caveats to this method, which we have tried to highlight throughout the presentation of the paper. First, and possibly most importantly, the RMTI cannot distinguish cases of technological expansion within a single region from geographic expansion. In these cases, e.g. when fishing has shifted from low to high intensity within the same geographic area, the RMTI will always identify a geographic expansion. We therefore suggest that the RMTI is best applied in areas where it is known that geographic expansion has occurred.

Secondly, the RMTI in the first region after the node is susceptible to estimation errors since it is calculated from the total reported catch. For example, an increase in overall reported catch after the node is reflected in a decrease in estimated RMTI in the first region. However, since the trophic levels of landed species in the first region are assumed to be lower than in newly expanded regions, we would expect the bulk of the reported catch to come from the first region. Similarly, the estimated catch in the first region is expected to decrease sharply when the reported MTI experiences a sharp increase. For example, when high trophic 
Fig. 10. Illustration of the region-based Marine Trophic Index (RMTI) for India. (a) Catch from 1950 to 2006, (b) the Fishing-in-Balance (FiB) index, (c) original MTI and (d) the RMTI (with 3 regions identified)
Fig. 11. Illustration of the region-based Marine Trophic Index (RMTI) for Venezuela. (a) Catch from 1950 to 2006, (b) the Fishing-in-Balance (FiB) index, (c) original MTI, (d) and the RMTI with 2 regions identified. The break in the light grey line illustrating the RMTI in Region 2 indicates a 'retraction period' where catches declined significantly from the late 1970 s through the early 1980 s
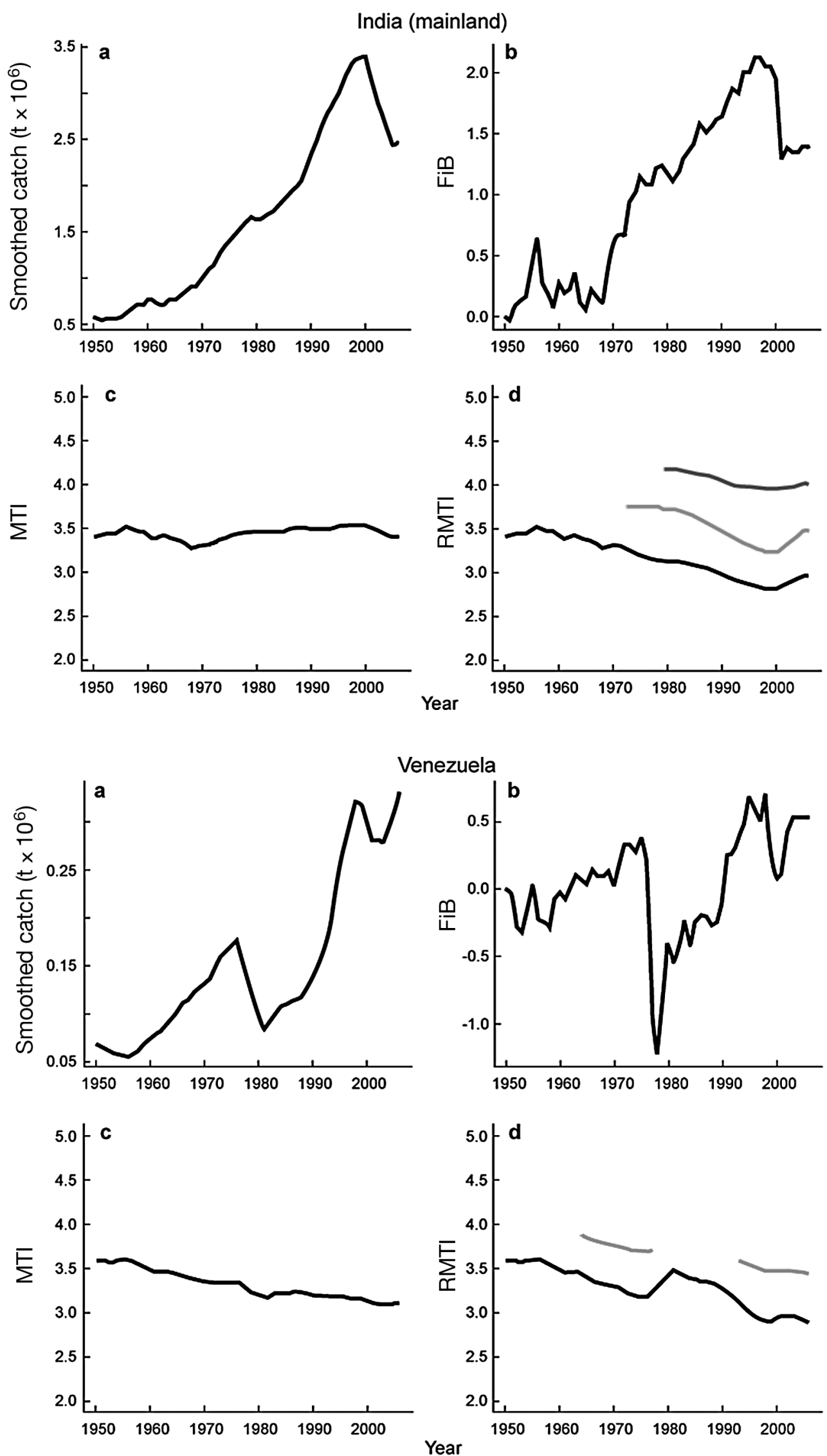
level species are fished in the new region extensively so that the overall MTI increases sharply, then we can assume that the bulk of the catch comes from the second region. Otherwise, if only a small proportion of the reported catch is of high trophic level species, then the reported MTI should not change perceptively. The RMTI model reflects these assumptions by reducing the catch allocation for the first region after the node and attributing a sharp increase in reported MTI to a larger amount of high trophic level species in the second region.

The RMTI has difficulty in determining the node year correctly when the catch in the second region increases gradually. In this case, the node year is identified later in the time series. We did not find an improvement in the node detection using a regime shift detection algorithm in place of the RMTI. Overall, we surmise that given the desire for fishers to have robust yields, if stocks in the first region are depleted and there is the ability to expand to new areas, the shift will likely be relatively fast. Therefore, the issue of catches gradually increasing as opposed to illustrating a more detectable jump may not be a significant problem.

Thus, we hope to have provided, with the RMTI, a tool to support further work on the fishing-down phenomenon, which continues to be a real problem, requiring quantification as a first step toward mitigation.

Acknowledgements. This is a contribution of the Sea Around Us, a scientific collaboration between the University of British Columbia and the Pew Charitable Trusts. We thank Dr. Wilf Swartz for the analysis on the geographic expansion of fisheries, which led to our Fig. 2, Dr. M.L.D. Palomares for the relationship between depth and trophic level, and Evelyn Liu for redrafting our figures.

\section{LITERATURE CITED}

Babouri K, Pennino MG, Bellido JM (2014) A trophic indicator toolbox for implementing an ecosystem approach in data-poor fisheries: the Algerian and Bou-Ismael Bay example. Sci Mar 78:37-51

Bellwood DR, Hughes TP, Folke C, Nyström M (2004) Confronting the coral reef crisis. Nature 429:827-833

Bhathal B (2005) Historical reconstruction of Indian marine fisheries catches, 1950-2000, as a basis for testing the 'Marine Trophic Index.' Fisheries Centre Research Reports Vol 13, No. 5. University of British Columbia, Vancouver

$>$ Bhathal B, Pauly D (2008) 'Fishing down marine food webs' and spatial expansion of coastal fisheries in India, 19502000. Fish Res 91:26-34

Branch TA, Watson R, Fulton EA, Jennings S and others (2010) The trophic fingerprint of marine fisheries. Nature 468:431-435
Caddy JF (1975) Spatial model for an exploited shellfish population and its application to the Georges Bank scallop fishery. J Fish Res Board Can 32:1305-1328

> Caddy JF, Csirke J, Garcia SM, Grainger RJR (1998) How pervasive is 'fishing down marine food webs?' Science 282:1383

Christensen V (1995) A model of trophic interaction in the North Sea in 1981, the year of the stomach. Dana 11:1-28

Christensen V, Pauly D (1993) Trophic models of aquatic ecosystems. ICLARM Conference Proceedings, Vol 26, International Center for Living Aquatic Resources Management, Manila

Coll M, Piroddi C, Steenbeek J, Kaschner K and others (2010) The biodiversity of the Mediterranean Sea: estimates, patterns, and threats. PLoS ONE 5:e11842

Essington TE, Beaudreau AH, Wiedenmann J (2006) Fishing through marine food webs. Proc Natl Acad Sci USA 103: 3171-3175

Frank KT, Petrie B, Choi JS, Leggett WC (2005) Trophic cascades in a formerly cod-dominated ecosystem. Science 308:1621-1623

Froese R, Kesner-Reyes K (2002) Impact of fishing on the abundance of marine species. ICES CM 2002:12. ICES, Copenhagen

Gascuel D, Labrosse P, Meissa B, Taleb Sidi MO, Guénette S (2007) Decline of demersal resources in North-West Africa: an analysis of Mauritanian trawl-survey data over the past 25 years. Afr J Mar Sci 29:331-345

Gelchu A, Pauly D (2007) Growth and distribution of portbased global fishing effort within countries' EEZs from 1970 to 1995. Fisheries Centre Research Report 15. University of British Columbia, Vancouver

Halpern BS, Walbridge S, Selkoe KA, Kappel CV and others (2008) A global map of human impact on marine ecosystems. Science 319:948-952

Hilborn R, Walters C (1992) Quantitative fisheries stock assessment: choice, dynamics and uncertainty. Chapman and Hall, New York, NY

Hutchings JA, Reynolds JD (2004) Marine fish population collapses: consequences for recovery and extinction risk. BioScience 54:297-309

ICAR (Indian Council of Agriculture Research) (1998) Vision-2020 CMFRI perspective plan. Indian Council of Agriculture Research, New Delhi

Jackson BC, Kirby MX, Berger WH, Bjorndal KA and others (2001) Historical overfishing and the recent collapse of coastal ecosystems. Ecology 84:162-173

Kleisner K, Pauly D (2011) The Marine Trophic Index (MTI), the Fishing in Balance (FiB) Index and the spatial expansion of fisheries. In: Christensen V, Lai S, Palomares M, Zeller D, Pauly D (eds) The state of biodiversity and fisheries in regional seas. Fisheries Centre Research Reports, Book 19(3). University of British Columbia, Vancouver, $\mathrm{p}$ 41-44

- Kleisner K, Zeller D, Froese R, Pauly D (2013a) Using global catch data for inferences on the world's marine fisheries. Fish Fish 14:293-311

Kleisner KM, Longo C, Coll M, Fogarty MJ and others (2013b) Exploring patterns of seafood provision revealed in the global Ocean Health Index. Ambio 42:910-922

Mendoza JJ, Marcano LA, Alio JJ, Arocha F (2010) Autopsy of the eastern Venezuela trawl fishery: analysis of landings and fishing effort data. Proc $62^{\text {nd }}$ Gulf and Caribbean Fisheries Institute, November 2-6, 2009, Cumana, Venezuela, p 69-76 
Morato T, Watson R, Pitcher TJ, Pauly D (2006) Fishing down the deep. Fish Fish 7:24-34

- Myers RA, Worm B (2003) Rapid worldwide depletion of predatory fish communities. Nature 423:280-283

O'Connor JS, Dewling RT (1986) Indices of marine degradation: their utility. Environ Manag 10:335-343

Pauly D (1995) Anecdotes and the shifting baseline syndrome of fisheries. Trends Ecol Evol 10:430

Pauly D (2010) Five easy pieces: the impact of fisheries on marine ecosystems. Island Press, Washington, DC

Pauly D, Christensen V (1993) Stratified models of large marine ecosystems: a general approach and an application to the South China Sea. In: Sherman K, Alexander LM, Gold BD (eds) Large marine ecosystems: stress, mitigation and sustainability. AAAS Press, Washington, DC, p 148-174

Pauly D, Christensen V (1995) Primary production required to sustain global fisheries. Nature $374: 255-257$

Pauly D, Chuenpagdee R (2003) Development of fisheries in the Gulf of Thailand Large Marine Ecosystem: analysis of an unplanned experiment. In: Hempel G, Sherman K (eds) Large marine ecosystems of the world 12: change and sustainability. Elsevier Science, Amsterdam, p 337-354

Pauly D, Palomares M (2005) Fishing down marine food webs: It is far more pervasive than we thought. Bull Mar Sci 76:197-211

Pauly D, Watson R (2005) Background and interpretation of the 'Marine Trophic Index' as a measure of biodiversity. Philos Trans R Soc Lond B Biol Sci 360:415-423

Pauly D, Christensen V, Dalsgaard J, Froese R, Torres F Jr (1998a) Fishing down marine food webs. Science 279: 860-863

Pauly D, Froese R, Christensen V (1998b) How pervasive is 'Fishing down marine food webs': response to Caddy et al. Science 282:183

Pauly D, Christensen V, Froese R, Palomares M (2000a) Fishing down aquatic food webs. Am Sci 88:46-51

Pauly D, Christensen V, Walters C (2000b) Ecopath, Ecosim, and Ecospace as tools for evaluating ecosystem impacts of fisheries. ICES J Mar Sci 57:697-706

> Pauly D, Palomares M, Froese R, Sa-a P, Vakily M, Preikshot D, Wallace S (2001) Fishing down Canadian aquatic food webs. Can J Fish Aquat Sci 58:51-62

> Pauly D, Watson R, Alder J (2005) Global trends in world fisheries: impacts on marine ecosystems and food security. Philos Trans R Soc Lond B Biol Sci 360:5-12

- Pauly D, Hilborn R, Branch TA (2013) Fisheries: Does catch reflect abundance? Nature 494:303-306

Rodionov SN (2005) A sequential method for detecting regime shifts in the mean and variance. In: Velikova V, Chipev N (eds) Large-scale disturbances (regime shifts) and recovery in aquatic ecosystems: challenges for management toward sustainability. UNESCO-ROSTE/BAS Workshop on Regime Shifts, 14-16 June 2005, Varna, Bulgaria, p 68-72

Scheffer M, Carpenter S, de Young B (2005) Cascading effects of overfishing marine systems. Trends Ecol Evol 20:579-581

Stergiou KI, Tsikliras AC (2011) Fishing down, fishing through and fishing up: fundamental process versus technical details. Mar Ecol Prog Ser 441:295-301

> Swartz W, Sala E, Tracey S, Watson R, Pauly D (2010) The spatial expansion and ecological footprint of fisheries (1950 to present). PLoS ONE 5:e15143

Vitousek PM, Mooney HA, Lubchenco J, Melillo JM (1997) Human domination of earth's ecosystems. Science 277 : 494-499

Walters CJ, Bonfil R (1999) Multispecies spatial assessment models for the British Columbia groundfish trawl fishery. Can J Fish Aquat Sci 56:601-628

> Watson RA, Morato T (2013) Fishing down the deep: accounting for within-species changes in depth of fishing. Fish Res 140:63-65

> Watson R, Kitchingman A, Gelchu A, Pauly D (2004) Mapping global fisheries: sharpening our focus. Fish Fish 5: 168-177

Watson R, Cheung WWL, Anticamara JA, Sumaila R, Zeller D, Pauly D (2013) Global marine yield halved as fishing intensity redoubles. Fish Fish 14:493-503

Proofs received from author(s): September 5, 2014 